\title{
LLNL-PROC-402933
}

LAWRENCE LIVERM ORE N A TIO N A L LABORATORY

\section{Combustion Effects in Confined Explosions}

A. L. Kuhl, H. Reichenbach

April 14, 2008

32nd International Symposium of Combustion Montreal, Canada

August 3, 2008 through August 8, 2008 
This document was prepared as an account of work sponsored by an agency of the United States government. Neither the United States government nor Lawrence Livermore National Security, LLC, nor any of their employees makes any warranty, expressed or implied, or assumes any legal liability or responsibility for the accuracy, completeness, or usefulness of any information, apparatus, product, or process disclosed, or represents that its use would not infringe privately owned rights. Reference herein to any specific commercial product, process, or service by trade name, trademark, manufacturer, or otherwise does not necessarily constitute or imply its endorsement, recommendation, or favoring by the United States government or Lawrence Livermore National Security, LLC. The views and opinions of authors expressed herein do not necessarily state or reflect those of the United States government or Lawrence Livermore National Security, LLC, and shall not be used for advertising or product endorsement purposes. 


\title{
Combustion effects in confined explosions
}

\author{
A. L. Kuhl ${ }^{1}$, H. Reichenbach ${ }^{2}$ \\ ${ }^{1}$ Lawrence Livermore National Laboratory, P.O. Box 808, Livermore, CA 94551 USA \\ ${ }^{2}$ Ernst Mach Institut, Eckerstraße 4, 79104 Freiburg, Germany
}

\begin{abstract}
Results of shock-dispersed-fuel (SDF) explosion experiments will be presented. The SDF charge consisted of a spherical 0.5-g PETN booster surrounded by 1-g of fuel: either flake Aluminum (Al) powder or TNT. The charge was placed at the center of a sealed chamber. Three cylindrical chambers (volumes of 6.6, 20 and 40 liters with $L / D=1)$ and three tunnels $(L / D=3.8,4.65$ and 12.5$)$ were used to explore the influence of chamber volume and geometry on completeness of combustion. Detonation of the SDF charge created an expanding cloud of explosion product gases and hot fuel (Al or TNT). When this fuel mixed with air, it formed a turbulent combustion cloud that consumed the fuel, and liberated additional energy $(31 \mathrm{~kJ} / \mathrm{g}$ for Al or $15 \mathrm{~kJ} / \mathrm{g}$ for TNT) over and above detonation of the booster $(6 \mathrm{~kJ} / \mathrm{g})$ that created the explosion. Static pressure gauges were the main diagnostic. Pressure and impulse histories for explosions in air were much greater than those recorded for explosions in nitrogen - thereby demonstrating that combustion has a dramatic effect on the chamber pressure. This effect increases as the confinement volume decreases and the excess air ratio approaches 2 to 3.5.
\end{abstract}

\section{Introduction}

Explored here are combustion effects occurring in confined explosions. For typical condensed explosives, the detonation wave in charge transforms the solid explosive into gaseous detonation products that are rich in carbon solid, carbon monoxide and hydrogen. These components can serve as a fuel that reacts when mixed with air via a turbulent combustion process. Combustion causes a dramatic increase in pressure in a confined explosion, thus pressure measurements and their associated impulses are used here as the main diagnostics to sense such combustion effects.

Ornellas measured the heat and products of detonation for 46 different explosives in a 5.3-liter spherical bomb calorimeter [1]. TNT illustrates this combustion effect most dramatically. For example, 25-gram TNT charges were detonated in vacuum conditions; an "explosion energy" of $1,093 \pm 11 \mathrm{cal} / \mathrm{g}$ was measured by the normal calorimetric method (temperature increase of a water bath). This value is in good agreement with heat of detonation $(1,133 \mathrm{cal} / \mathrm{g})$ as predicted by the thermodynamic equilibrium code Cheetah [2]. In companion experiments, 25-g TNT charges were detonated in a pressurized oxygen atmosphere (2.46 bars). An explosion energy of $3,575 \pm 35 \mathrm{cal} / \mathrm{g}$ was measured; this value is in good agreement with the "heat of combustion" for TNT in air $(3,594 \mathrm{cal} / \mathrm{g})$ as predicted by the Cheetah code. While these tests experimentally confirmed the heats of detonation and combustion of many explosives, they did not provide any information on the temporal evolution of the explosion energy.

To remedy this situation, we previously studied afterburning of TNT detonation products in air on a larger scale: $1-\mathrm{kg}$ cylindrical TNT charges were detonated in a $16-\mathrm{m}^{3}$ cylindrical chamber [3]. Pressure histories for 
explosions in air were much larger than those measured for explosions in nitrogen - thereby demonstrating a strong combustion effect. Gasdynamic aspects of this combustion process have been studied via numerical simulations [4]. The corresponding combustion locus in thermodynamic state space has been found by Kuhl [5]. The gas-dynamic model [4] has been extended to model two-phase combustion effects associated with Al-SDF explosions $[6,7,8]$. The two-phase model takes into account two global reactions: combustion of $\mathrm{Al}$ particles with air, and afterburning of PETN detonation products gases with air. Computed pressure histories were in good agreement with measured pressure records - thereby proving that the twophase model adequately describes the confined combustion process for this strongly over-driven system.

Reported here are the results of parametric laboratory experiments performed with 1.5-gram Shock-Dispersed-Fuel (SDF) charges. Both TNT and Aluminum (Al) powder were used as fuels. A booster charge is used to disperse the fuel in air (or nitrogen), ignite it, and induce an exothermic energy release via a turbulent combustion process $[9,10]$. Previous studies have shown that the combustion completeness depends on both the chamber volume and geometry [11,12] so six different chambers were employed. We refer to them as barometric calorimeters since we use pressure measurements to diagnose the energy evolution in the explosion. Experiments with TNT-SDF charges illustrate afterburning of TNT in air, while experiments with Al-SDF charges demonstrate the pressure effects of Aluminumair combustion. Previous studies [13,14] compared waveforms measured in TNT explosions in air and nitrogen with each other, and Al-SDF explosions in air and nitrogen with each other-to demonstrate the combustion effect. Here we will compare waveforms for AlSDF explosions with TNT explosions to demonstrate that they produce similar impulses-even though the heat of combustion of Al-air is twice that of TNT-air. Mean chamber pressures will be deduced from fits to impulse histories. We will show how the mean chamber pressure scales as a function of chamber volume and geometry $(L / D)$. And the mass fraction of Products produced by combustion will be plotted versus excess air ratio, to demonstrate how these effects scale to other conditions.

\section{Experiments}

Experiments were conducted in 6.6-, 21.2- and 40.5-liter cylindrical calorimeters (Fig. 1) and calorimetric tunnels with $\mathrm{L} / \mathrm{D}=4.65$, 12.5 and 3.9 (Fig. 2); dimensions are given in figure captions.

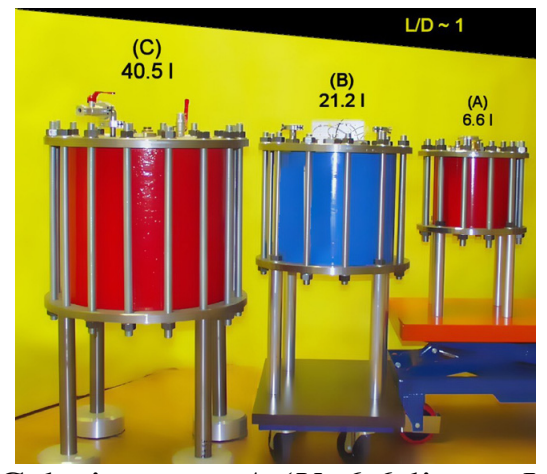

Fig. 1. Calorimeters: $A$ ( $V=6.6$ liters: $L=21 \mathrm{~cm}$, $D=20 \mathrm{~cm}, L / D=1.05), B(V=21.2$ liters: $L=30$ cm, $D=30 \mathrm{~cm}, L / D=1.00)$ and $C(V=40.5$ liters: $L=37.9 \mathrm{~cm}, D=36.9 \mathrm{~cm}, L / D=1.03)$.

The SDF charge construction is shown in Fig. 3. It begins with a $0.5-\mathrm{g}$ spherical PETN booster (initial density of $1 \mathrm{~g} / \mathrm{cc}$ ). The booster is surrounded by fuel. For the composite charge, the fuel consists of $1.0-\mathrm{g}$ spherical shell of TNT (initial density of $1.0 \mathrm{~g} / \mathrm{cc}$ ). For the Al-SDF charge, the booster is surrounded by a thin paper cylinder, and the void space is filled with $1.0-\mathrm{g}$ of flake Aluminum (initial bulk density of 0.63 $\mathrm{g} / \mathrm{cc}$ ). SEM photographs of the Al powder indicate a flake-like structure of characteristic dimension 100 microns and a thickness of 1 micron (Fig. 4). According to the manufacturer (Merk, AG) the Al content of the powder was more than $93 \%$ by mass. The booster is 
detonated by an exploding bridge wire located at the charge center (e.g., see Fig. 3a). Detonation of the booster created an expanding fuel cloud of explosion products gases and hot aluminum particles (or TNT detonation products gases). When this fuel mixed with air, it formed a turbulent combustion cloud that consumed the aluminum (or TNT products), and liberated 31 $\mathrm{kJ} / \mathrm{g}$ (or $14.5 \mathrm{~kJ} / \mathrm{g}$ for TNT) of energy in addition to the energy of the booster that created the explosion. Explosions in a nitrogen atmosphere (which eliminates oxidation) allow one to confirm the heat of detonation of the charge, while explosions in an air atmosphere allow one to study the dynamics of afterburning and combustion in a confined explosion.

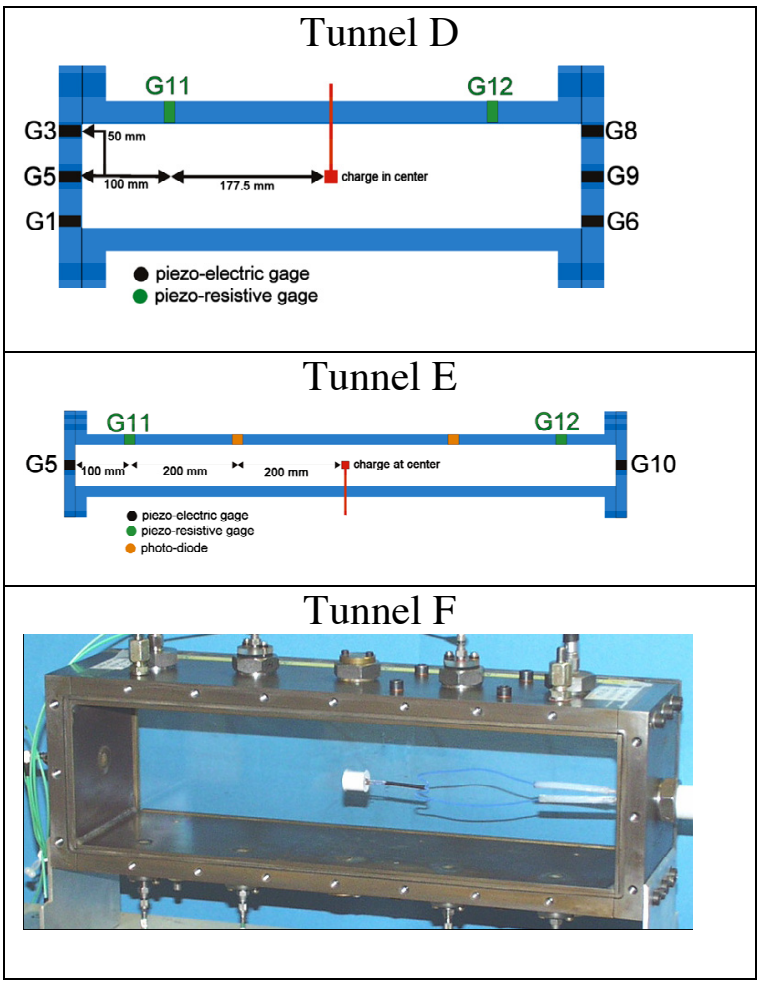

Fig. 2. Tunnels: $D$ (circular, $\mathrm{d}=12 \mathrm{~cm}, \mathrm{~L}=55.5$ $\mathrm{cm}, \mathrm{V}=6.3-\mathrm{l}, \mathrm{L} / \mathrm{D}=4.65), E(\mathrm{x}=\mathrm{y}=8 \mathrm{~cm}, \mathrm{~L}=100$ $\mathrm{cm}, \mathrm{V}=6.3-1, \mathrm{~L} / \mathrm{D}=12.5)$ and $F(\mathrm{x}=\mathrm{y}=10.1 \mathrm{~cm}$, $\mathrm{L}=38.6 \mathrm{~cm}, \mathrm{~V}=3.98-1, \mathrm{~L} / \mathrm{D}=3.8$ ).

The SDF charge was placed at the center of the chamber. The main diagnostic consisted of 8 piezo-electric crystal pressure gages (Kistler 603B); their fast response was needed to capture the shock front details. For calorimeters they were located at 5 and $7.5 \mathrm{~cm}$ radii on the lid of the vessel; for tunnels, gauges (labeled G1-G12) were located on the side-wall and end-wall of the tunnel. Flame temperatures of 4,000 $\mathrm{K}$ are possible for $\mathrm{Al}$-air combustion cases. So gages based on a different measurement principle-the piezo-resistive effect (Kistler 4075A) were also used. While they have rise time that is too slow to measure the shock front accurately, they have no thermal drift, and a useful for measuring pressures in high-temperature environment for long times. All gages were recessed by $0.1 \mathrm{~mm}$ and filled with a silicon rubber for thermal protection.

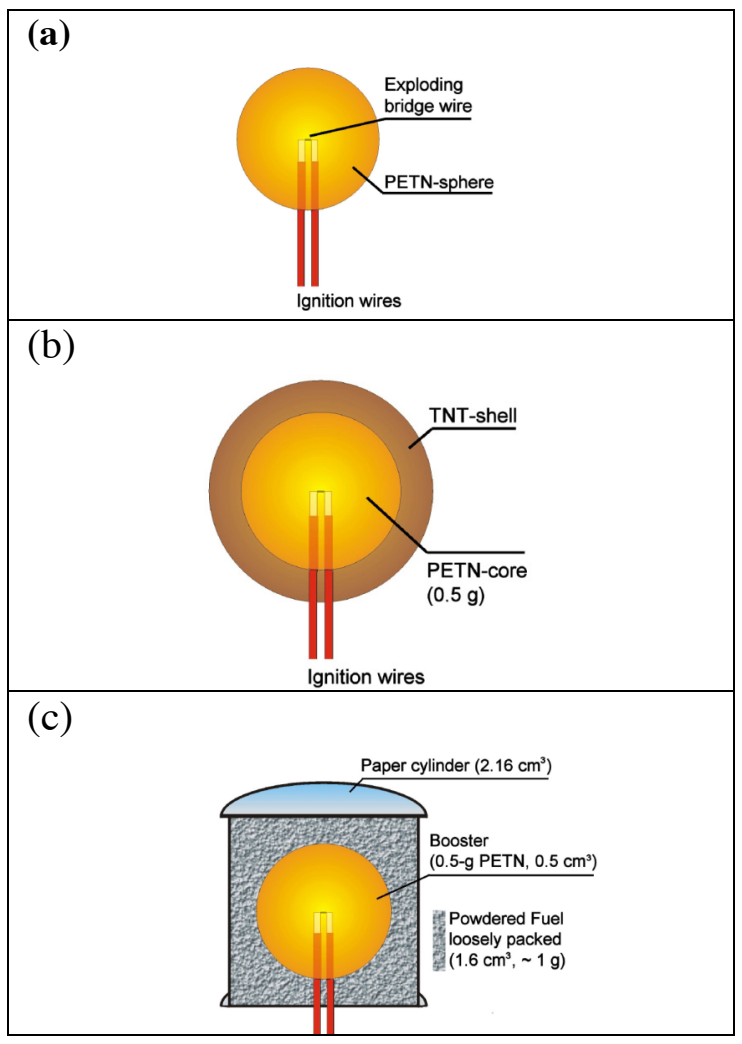

Fig. 3. Charge construction: (a) 0.5-g PETN booster charge; (b) composite charge (0.5-g PETN booster + 1-g TNT shell); (c) Al-SDF charge (0.5-g PETN booster + 1-g Aluminum).

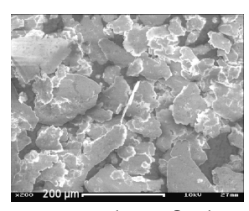

Fig. 4. SEM photograph of the flake Aluminum powder (Merk, AG). 

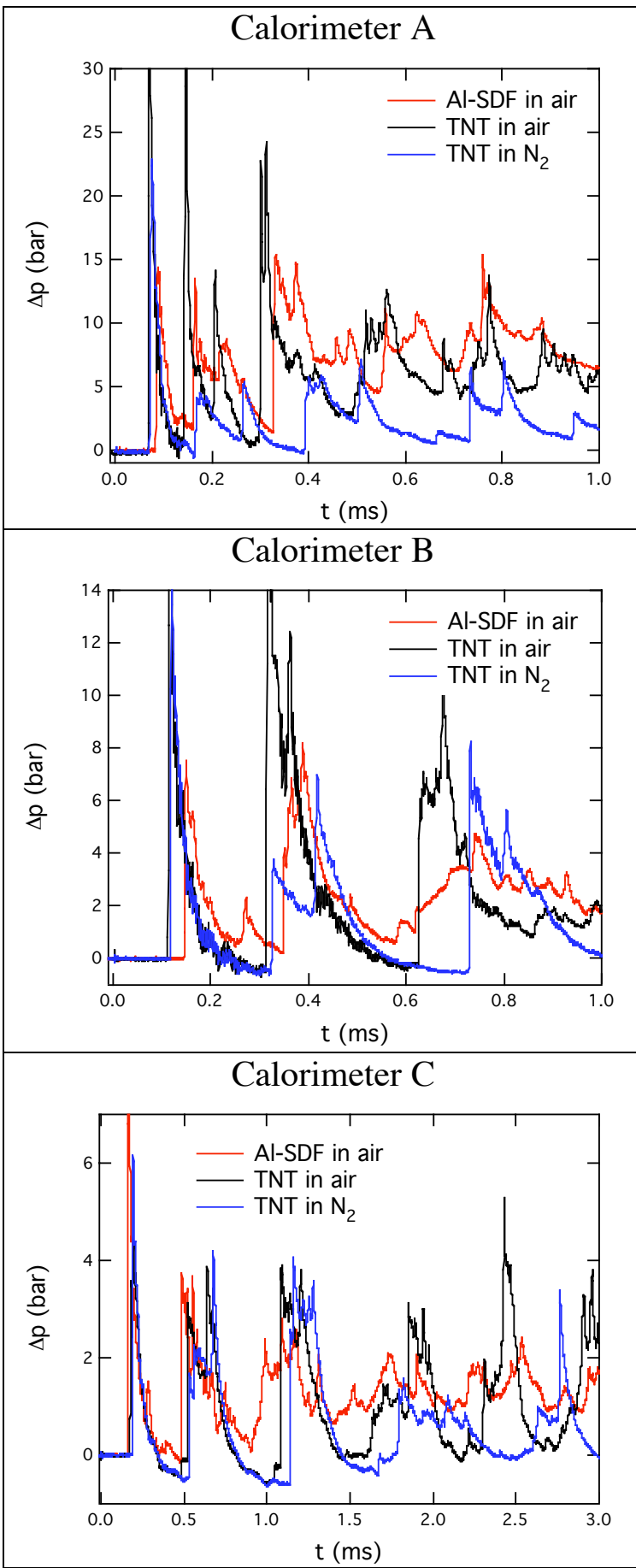

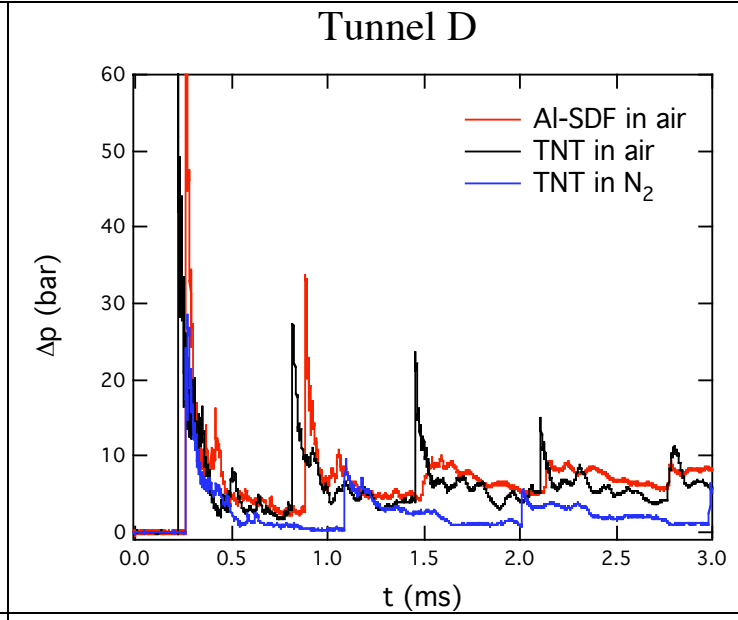

Tunnel E

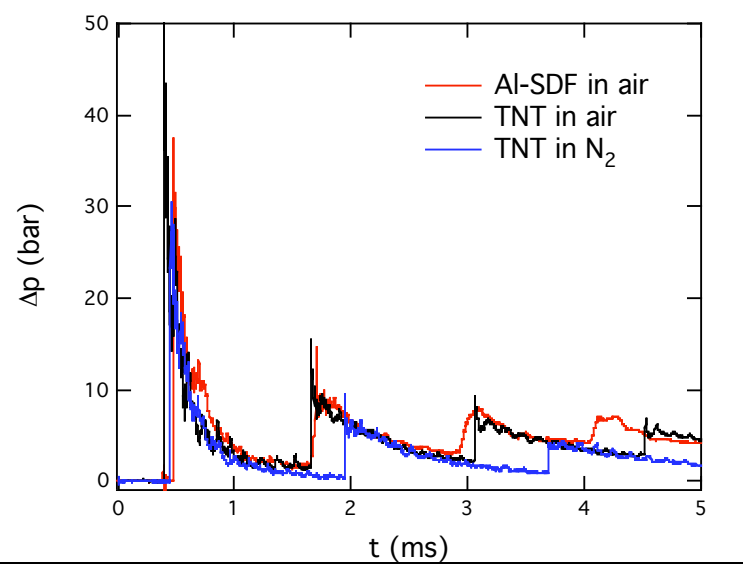

Tunnel F

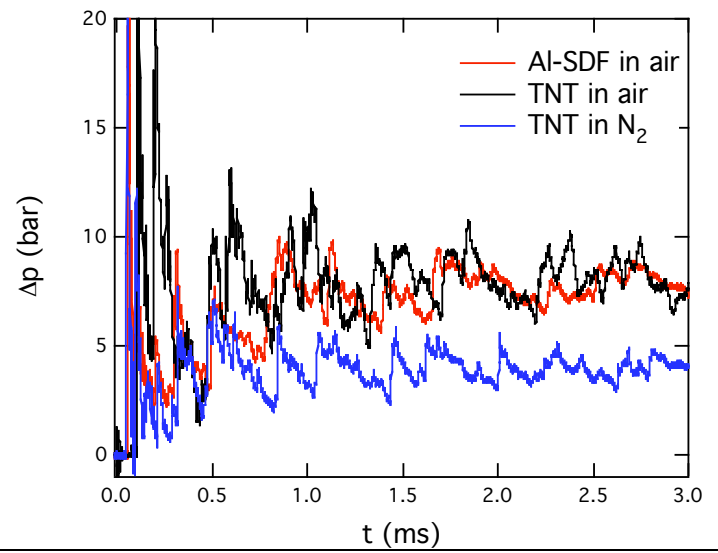

Fig. 5 Comparison of pressure histories measured in the chambers $A-F$. Red curves denote results from 1.5-g Al-SDF explosions in air, black curves represent results from 1.5-g composite TNT charges in air, and blue curves correspond to 1.5-g composite TNT charges in nitrogen. Pressure enhancement (red and black curves versus blue curves) is a consequence of combustion of the explosion products gases with air. 


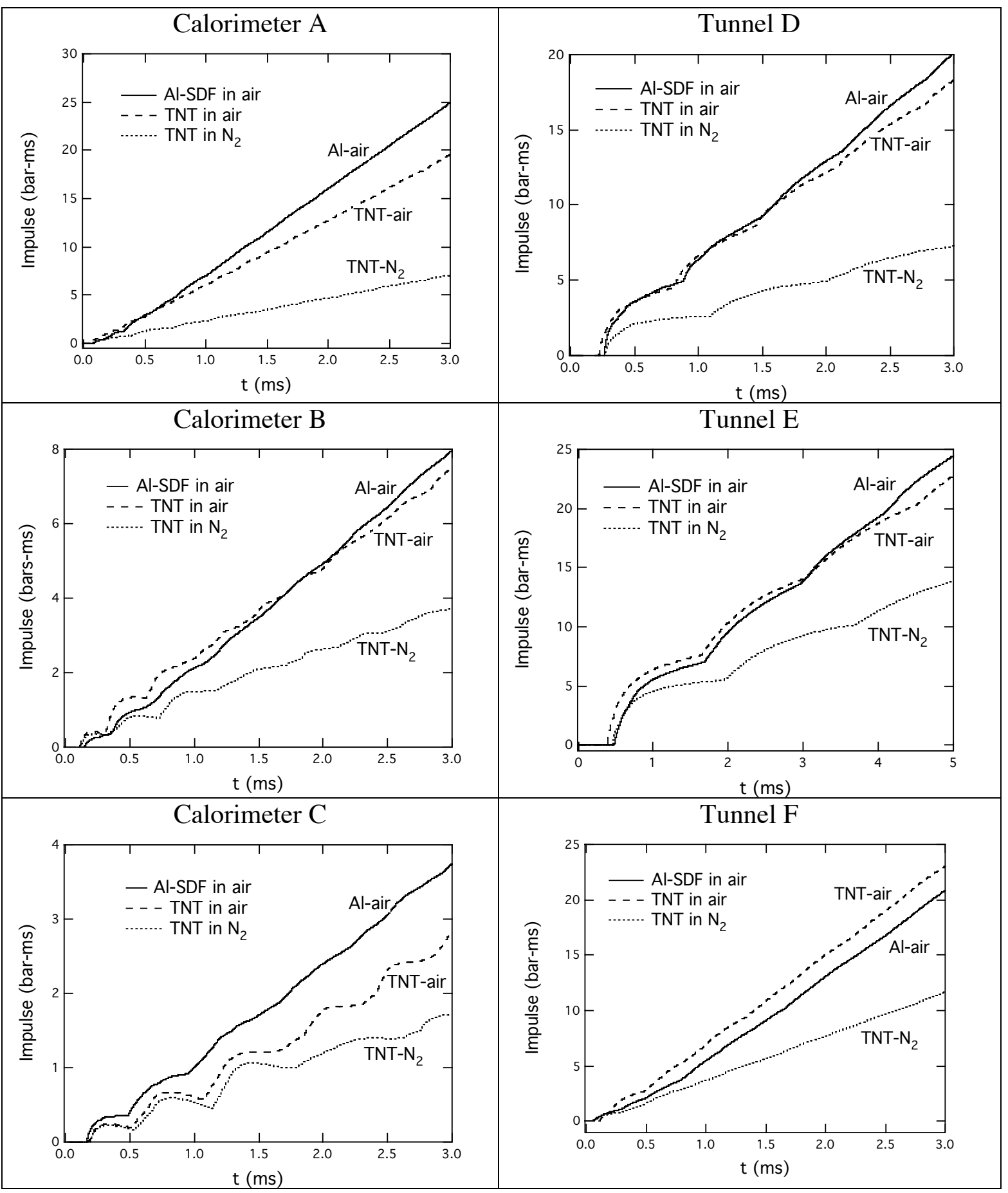

Fig. 6 Impulse histories corresponding to measured pressure histories in Fig. 5. Impulse enhancement is a consequence of combustion of the explosion products gases with air. 


\section{Results}

Figure 5 presents a comparison of pressure histories measured in chambers $A-F$. Red curves denote results from 1.5-g Al-SDF explosions in air; black curves represent measurements for 1.5-g composite TNT explosions in air; and blue curves correspond to $1.5 \mathrm{-g}$ composite TNT explosions in nitrogen. Pressure enhancement (i.e., the red and black curves versus the blue curves) is a consequence of combustion of the explosion products gases with air. This combustion effect depends on chamber volume and on the chamber geometry. This effect is most pronounced in smaller chambers $(A$ and $F)$, where the confinement enhances the conditions required for sustained combustion.

Figure 6 depicts the impulse histories corresponding to the measured pressure histories of Fig. 5. They were calculated according to the standard definition: $I_{k}(t)=\int_{0}^{t} \Delta p_{k}\left(t^{\prime}\right) d t^{\prime} \quad$ where $k$ denotes the explosion case: $k=\left\{A l-\right.$ air,$T N T-$ air,$\left.T N T-N_{2}\right\} . \quad$ The impulse histories show this combustion effect more quantitatively than the pressure histories. Impulses for confined explosions in air are 2-3 times larger than those for explosions in nitrogen.

\section{Discussion}

The impulse histories of Fig. 6 were fit with linear functions of time: $I_{k}(t)=a_{k}+\Delta \bar{p}_{k} \cdot t$. Note that the slope $\Delta \bar{p}_{k}$ represents the late-time mean chamber pressure. These values are presented in Fig. 7 as a function of chamber volume. In the following analysis, the average atmospheric conditions $\left(p_{a}=0.9777\right.$ bars, $T_{a}=291 \mathrm{~K}$ ) of the Ernst Mach laboratory were used. The measured values (closed symbols and dashed lines) are compared with thermodynamic predictions of Constant-Volume-Explosions, $C V E$, (open symbols and solid lines) based on the Cheetah code [2]. If all the fuel were consumed by combustion with air, then the closed symbols would coincide with the open systems. Such is not the case; actual fuel consumption will be quantified below (Fig. 9). Nevertheless, mean chamber pressures are considerably larger than those measured for TNT in Nitrogen (lower curve).

Mean chamber over-pressures and $C V E$ predictions are presented in Fig. 8 as a function of tunnel $L / D$ (notation is the same as in Fig. 7). This figure shows that combustion completeness decreases with increasing $L / D$ at constant volume $(V=6.3$ liters $)$. Nevertheless, mean chamber pressures are considerably larger than those measured for TNT in Nitrogen (lower curve) - even at $L / D=12.5$.

From the thermodynamic model of combustion in explosions [5], one can show the mean chamber pressure depends linearly on the mass fraction of combustion Products: $Y_{p}$ according to the relation: $\bar{p}_{c}(t)=p_{R}+Y_{P}(t)\left[p_{P}-p_{R}\right]$, where $p_{R}$ and $p_{P}$ denote the Reactants and Products pressures that may be evaluated by Cheetah code calculations of constant volume explosions in Nitrogen and air, respectively. By solving for $Y_{p}$ and evaluating the expression at late times $(\sim 5 \mathrm{~ms})$, one can determine the final mass fraction of Products in the chamber: $Y_{P, c}=\left[\bar{p}_{c}-p_{R}\right] /\left[p_{P}-p_{R}\right]$. Values of $Y_{P, c}$ are plotted in Fig. 9 as a function of excess air ratio: $\chi$. It shows that for a wide range of stoichiometries $\quad(1<\chi<14), \quad$ combustion consumes from $50-90 \%$ of the fuel and transforms it into Products whose presence can be measured with pressure gages. Products production reaches a maximum under lean conditions: for Al-air, it occurs at $\chi_{A l}=2$, while for TNT-air it occurs at $\chi_{T N T}=3.5$ (see the lognormal fits in the figure caption).

An isobaric scaling law was proposed: $\Pi \equiv E_{2} V_{1} / E_{1} V_{2}$ (where $E$ and $V$ denote energy and volume in the chamber) Experiments were performed to test the hypothesis that $\Pi=1$. Results are given in Table 1. For example, $0.5-\mathrm{g}$ and $1.0 \mathrm{-g}$ booster charges were detonated in the 21.2-liter and 40.5 liter calorimeters; mean 
chamber over-pressures agreed within 3.4 $4 \%$. Next 1.5-g and 3-g Al-SDF charges were detonated in the 21.2-liter and 40.5-liter calorimeters; mean chamber over-pressures agreed with $10 \pm 7 \%$. Similar agreement $(10 \pm 4$ $\%)$ was found for 3-g and 6-g Al-SDF charges. The isobaric scaling $\Pi=1$ is valid within $10 \pm 7$ $\%$, over the range of conditions tested.

We have considered other moreenergetic materials (e.g., polyethylene, magnesium boride, aluminum hydride and zirconium) that might serve as fuels for SDF explosions. Although they have heats of combustion from 7-10 $\mathrm{kCal} / \mathrm{g}_{F}$, they typically have lower adiabatic flame temperatures than Al-air systems (except for Zirconium: $\left.T_{a d}=4,300 \mathrm{~K}\right)$. This is because they require more air (i.e., have larger stoichiometric air-fuel ratios, $\sigma_{s}$ ) than Al-air (except for Zirconium with $\left.\sigma_{s}=1.6\right)$. The Al-air system seems to maximize the combustion effect, for fuels considered.

\section{Conclusions}

Experiments with 1.5-g SDF charges have been conducted in six different chambers. Pressure and impulse histories for explosions in air were significantly larger than those in nitrogen - thereby demonstrating a strong combustion effect. In four out of the six cases, Al-SDF charges and TNT composite charges gave similar impulse enhancements due to combustion. This effect decreased with increasing chamber volume and L/D (presumably due to quenching). Combustion completeness (i.e., mass fraction of Products) reached a maximum of $Y_{P, c}=88 \%$ when the excess air ratio was between 2 and 3.5. An isobaric scaling law: $\Pi \equiv E_{2} V_{1} / E_{1} V_{2}$ was shown to be valid within $10 \pm 7 \%$, over the range of conditions tested.

\section{Acknowledgements}

This work performed under the auspices of the U.S. Department of Energy by Lawrence Livermore National Laboratory under Contract DE-AC52-07NA27344.

\section{References}

[1] D. L. Ornellas, Calorimetric Determination of the Heat and Products of Detonation for Explosives: October 1961 to April 1982, LLNL, Report No. UCRL-52821, Lawrence Livermore National Laboratory, 1982.

[2] L. E. Fried, CHEETAH 1.22 User's Manual, Report No. UCRL-MA-117541, Lawrence Livermore National Laboratory, 1995.

[3] A. L. Kuhl, J. W. Forbes, J. B. Chandler, Afterburning of Detonation Products from TNT Charges in a $16-\mathrm{m}^{3}$ Chamber, Energetic Materials: Reaction of Propellants, Explosives and Pyrotechnics, $34^{\text {th }}$ Int. Annual Conference of ICT, June 2003, Fraunhofer Institut Chemicsch Technologie, Pfinztal, Germany (2003) 9.1-9.14.

[4] A. L. Kuhl, R. E. Ferguson, A. K. Oppenheim, Gasdynamics of Combustion of TNT Products in Air, Archivum Combustionis 19:1-4 (1999) 67-89.

[5] A. L. Kuhl Thermodynamics of Combustion of TNT Products in a Chamber ХИМИУЕСКАЯ ФИЗИКА (Chemical Physics, RAS) Tom $25 N^{\circ} 10$, (2006) 42-48.

[6] A. L. Kuhl, J. B. Bell, V. E. Beckner, B. Khasainov, Simulation of Aluminum combustion and PETN afterburning in a confined explosion, Twenty-First Int. Colloquium on Dynamics of Explosions and Reactive Systems, Poitiers, France (2007).

[7] A. L. Kuhl, J. B. Bell, V. E. Beckner, B. Khasainov, Numerical Simulations of Thermobaric Explosions, Energetic Materials: Characterization and Performance of Advanced Systems, $38^{\text {th }}$ Int. Annual Conf. of ICT, Fraunhofer Inst. Chemicsch Technologie, Pfinztal, Germany (2007) 1.1-14.

[8] J.B. Bell, A. L, Kuhl, V.E. Beckner, Simulation of Enhanced-Explosive Devices in Chambers and Tunnels, HPCMP Users Group Conference 20007, 0-7695-30885/07, IEEE.

[9] P. Neuwald, H. Reichenbach, A. L. Kuhl, Shock-Dispersed Fuel Charges-Combustion in Chambers and Tunnels, Energetic 
Materials: Reaction of Propellants, Explosives and Pyrotechnics, $34^{\text {th }}$ Int. Annual Conf. of ICT, Fraunhofer Inst. Chemicsch Technologie, Pfinztal, Germany (2003) 13.1-14.

[10] P. Neuwald, Explosively Driven Combustion of Shock-Dispersed Fuels, Proceedings of American Physical Society Topical Conference on Shock-Compression of Condensed Matter, AIP Conference Proceedings 845: part 1 (2005) 976-981.

[11] A. L. Kuhl, P. Neuwald, H. Reichenbach, Effectiveness of Combustion of ShockDispersed Fuels in Calorimeters of Various Volumes, Combustion, Explosion and Shock Waves, 42:6 (2006) 731-734.

[12] A. L. Kuhl, R. E. Ferguson, A. K. Oppenheim, T Sum, H. Reichenbach, P. Neuwald, Effects of Confinement on Combustion of TNT Explosions Products in Air, Archivum Combustionis 21:1 (1999) 3-25.

[13] H. Reichenbach, P. Neuwald, A. L. Kuhl, Afterburning and Combustion in Explosions in Barometric Calorimeters. ibid [6], (2007).

[14] H. Reichenbach, P. Neuwald, A. L. Kuhl, Waveforms measured in confined thermobaric explosions, ibid [7], (2007) 3.1-3.11.

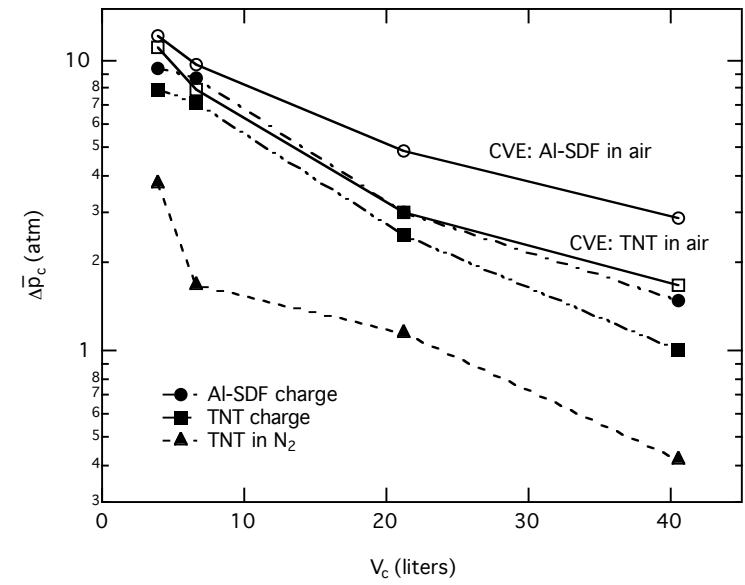

Fig. 7. Comparison of the measured mean chamber overpressures (closed symbols) with thermodynamic predictions of ConstantVolume-Explosions (CVE) (open symbols) as a function of chamber volume $\left(p_{a}=0.977 \mathrm{bar}\right.$, $T_{a}=291 \mathrm{~K}$ ).

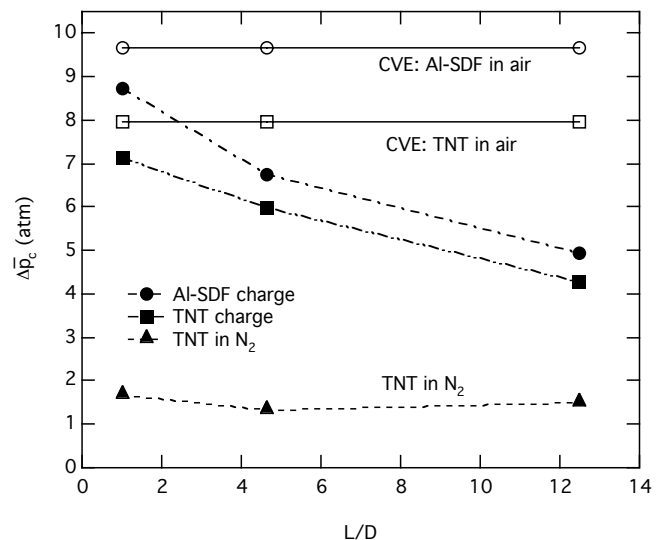

Fig. 8. Comparison of the measured mean chamber overpressures (closed symbols) with thermodynamic predictions of ConstantVolume-Explosions (CVE) (open symbols) as a function of tunnel L/D with $V_{c}=6.3$ liters ( $p_{a}=0.977$ bar, $\left.T_{a}=291 \mathrm{~K}\right)$.

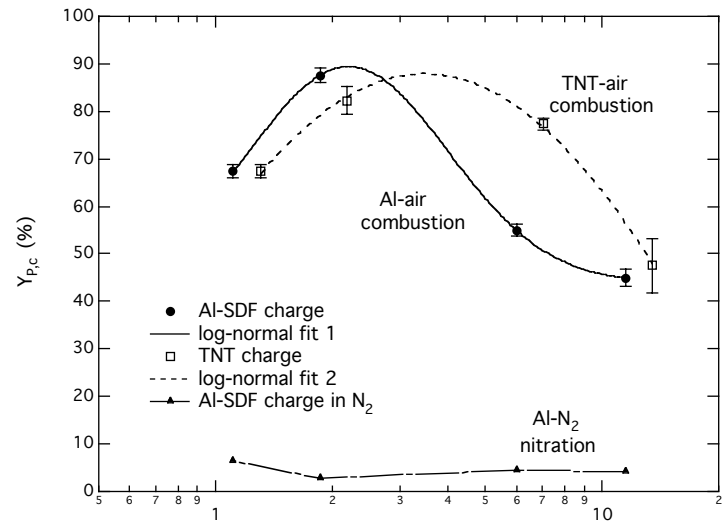

Fig. 9. Mass fraction of combustion Products: $Y_{p, c}$ as a function of excess air ratio: $\chi$. Lognormal curve fits are:

fit 1: $43+44 * \exp \left[-\{\ln (\chi / 2) / 0.95\}^{2}\right]$

fit 2: $-316+404 * \exp \left[-\{\ln (\chi / 3.5) / 4.2\}^{2}\right]$

Table 1. SDF Explosions at $E / V=$ constant

\begin{tabular}{|c|c|c|c|c|}
\hline $\begin{array}{c}\text { Booster } \\
(\mathrm{g})\end{array}$ & $\begin{array}{c}\text { Fuel } \\
(\mathrm{g})\end{array}$ & $\begin{array}{l}\Delta \bar{p}_{c} \text { (bar) } \\
V=21-1\end{array}$ & $\begin{array}{l}\Delta \bar{p}_{c}(\text { bar } \\
V=40-1\end{array}$ & $\begin{array}{c}\Pi-1 \\
(\%)\end{array}$ \\
\hline $0.5 \mathrm{~s}^{\mathrm{a}}$ & 0 & 0.698 & - & \multirow{2}{*}{$3 \pm 4$} \\
\hline $1 c^{b}$ & 0 & - & 0.722 & \\
\hline $0.5 \mathrm{~s}^{\mathrm{a}}$ & $1 \mathrm{Al}$ & 3.736 & - & \multirow{2}{*}{$10 \pm 7$} \\
\hline $1 c^{b}$ & $2 \mathrm{Al}$ & - & 4.112 & \\
\hline $1 c^{b}$ & $2 \mathrm{Al}$ & 6.349 & - & \multirow{2}{*}{$10 \pm 4$} \\
\hline $2 c^{b}$ & $4 \mathrm{Al}$ & - & 6.999 & \\
\hline
\end{tabular}

